\title{
Sobre o gênio na estética de Schopenhauer
}

\author{
Maria Lúcia Cacciola \\ Universidade de São Paulo (USP) - São Paulo
}

\begin{abstract}
RESUMO
Minha comunicação pretende apresentar um estudo da figura do gênio em Schopenhauer. A preocupação fundamental será a questão da especificidade da obra de arte em Schopenhauer como modo de conhecimento, a saber, "como metafísica do belo". Nessa via analisaremos a característica própria do gênio em Schopenhauer, buscando estabelecer suas referências ao gênio em Kant, e questionando as afinidades e contrastes entre ambas as concepções. Trata-se de inquirir, por meio da filosofia da arte de Schopenhauer, se o gênio, na concepção pós-kantiana, guarda as mesmas características que as que lhe foram atribuídas por Kant na terceira Crítica. A intenção é a de pesquisar o alcance dessa questão diante da acusação de uma volta de Schopenhauer a uma posição pré-crítica.
\end{abstract}

\begin{abstract}
This presentation consists in a study on the notion of genius in Schopenhauer. To this purpose I concentrate attention on the specificity of the author's conception of the work of art as a mode of knowledge, i.e., "as a metaphysics of beauty". Within this scope I analyze the proper characteristic of genius in Schopenhauer's philosophy, targeting to establish his references to genius as conceived by Kant. Such analysis makes it possible to consider the affinities and contrasts existing between both conceptions, which by its turn allow us to inquire - through Schopenhauer's philosophy - whether the post-Kantian conception of genius preserves the characteristics that Kant attributed to it in the third Critique. My general intention is to explore the possibilities of this question as one of the keys to evaluate the accusation done to Schopenhauer that he would have retrogressed to a pre-critical position.
\end{abstract}

A metafísica do belo em Schopenhauer é um modo de conhecer que se diferencia do conhecimento do senso comum e das ciências, ao ter como referência a objetivação da vontade na Ideia.

Trata-se assim de um conhecimento que parte do sujeito, e nisso Schopenhauer acompanha Kant, a quem reconhece o grande mérito de ter dado à arte "uma direção subjetiva" pelo sentimento de prazer e desprazer, e não de explicá-la como uma qualidade do objeto. O belo e o sublime desde Kant não são atributos de um objeto, mas se referem a um estado do sujeito. ${ }^{1}$

\footnotetext{
${ }^{1}$ Schopenhauer, A. Kritik der kantischen Philosophie" Haffmans Taschenbuch, Leipzig, 1988, p. 670. Tradução, Ed. Abril, São Paulo, 1980, p. 178.
} 
O mérito de Kant é o da investigação da própria emoção, "em consequência da qual chamamos belo o objeto que a ocasiona e de descobrir as partes essenciais e as suas condições na nossa mente. Por isso sua investigação tomou inteiramente a direção subjetiva."

Kant teria apenas mostrado o caminho, dado o método dessa investigação, mas não teria atingido o alvo, a saber, a verdade objetiva, atingida a partir desse sentimento subjetivo.

Kant não teria atingido o alvo por ter seguido o seu método de privilegiar a abstração, pondo o conhecimento abstrato como base do intuitivo, partindo das formas do juízo como chave do conhecimento de nosso mundo intuitivo; e, aqui, Schopenhauer reproduz a mesma crítica que faz à Crítica da razão Pura, pois Kant, fiel ao amor pela simetria, procura reproduzir na estética a mesma ordem da primeira Crítica. Ao belo, chega-se pelo juízo estético, juízo que manifesta um processo no sujeito, partindo do chamado juízo de gosto, aliás, um nome de muito mau gosto, como ironiza Schopenhauer. ${ }^{3}$ O problema de Kant é o de ter, apesar das soluções engenhosas encontradas, ficado abaixo da dignidade do seu objeto, o belo. Isto, por exemplo, quando busca estabelecer uma validade tão universal a esse processo subjetivo, por meio do juízo de gosto, dando a impressão de que se trata de uma propriedade do objeto. Kant parte do juízo sobre o belo e não imediatamente do sentimento do belo, como se o belo surgisse da enunciação dos outros e não da sua própria intuição. Além do amor à simetria, o fato de Kant impressionar-se mais com o juízo sobre o belo do que com o próprio belo ${ }^{4}$, talvez se deva à falta de ocasião, apontada por Schopenhauer, de ter contato com sequer uma obra de arte significativa, ${ }^{5}$ no seu exílio voluntário em Koenigsberg. Nisso sem dúvida, Schopenhauer como filósofo, por assim dizer, cosmopolita, teria levado vantagem, ao conviver na viagem à Europa e ainda em Berlim, Weimar, Frankfurt e Dresden, cidades onde viveu, com obras de arte importantes... Aliás, ele se admira, não sem uma ponta de ironia, de como Kant apesar desse fato conseguiu "um mérito tão grande e durável na consideração da arte e do belo" 6 .

\footnotetext{
${ }^{2}$ Idem, ibidem. "In Folge welcher wir das verlassende Objekt SCHON nennen, ernstlich und tief zu untersuchen, um, wo möglich, die Bestandteile und Bedingungen derselben in unserm Gemüth aufzufinden. Seine Untersuchungen nahm daher ganz die subjective Richtung."

${ }^{3}$ Idem, ibidem. p. 671.

${ }^{4}$ Idem, ibidem. p. 671.

${ }^{5}$ Idem, ibidem. p. 669.

${ }^{6}$ Idem, ibidem. p. 669.
} 
Apesar de muitas observações verdadeiras, a solução que deu para sua teoria do belo foi considerada insuficiente por Schopenhauer. O mesmo figurino da Crítica da razão pura é adaptado forçadamente ao todo, o que se mostra, por exemplo, na antinomia do juízo estético, onde Kant deduz o que é o belo. Mas Schopenhauer nota que, para manter tal simetria, Kant cria uma faculdade de juízo inteiramente peculiar, a reflexionante. Deixando de lado as críticas que podem ser feitas e de fato o são ao nosso autor, a de não ter entendido em Kant o alcance da reflexão como instância pré-lógica e o papel que Kant atribui à imaginação em jogo com o entendimento no juízo de gosto e, por fim, a especificidade própria de tal juízo, vamos nos deter no que pretende Schopenhauer desse tipo de conhecimento distinto do expresso no primeiro livro do Mundo, que se baseia no princípio de razão.

Em Schopenhauer, o conhecimento estético é objetivo, pois dado por meio da objetivação das Ideias, mas que parte de um sujeito cognoscente "puro" (rein Subjekt des Erkennens), por isso despido de qualquer referência a objetos que se relacionam entre si no domínio do conhecimento científico e do senso comum, por meio das modalidades do princípio de razão. Trata-se, pois, de uma representação de tipo especial, um sujeito puro que se refere a um objeto também "puro", isto é, destacado quer das cadeias causais das representações intuitivas, quer das cadeias dedutivas das representações abstratas. A este sujeito é atribuída a qualidade de gênio, pelo tipo especial de conhecimento que propicia, através da Ideia estética que realiza a fusão sujeito e objeto, só possível no caso da ausência da mediação pelo princípio de razão. O que marca o gênio é, pois, a possibilidade de desinteressar-se, isto é de destacar seu conhecimento da multiplicidade de objetos que só existe enquanto ligada entre si e que constitui o teatro das aparências. A liberdade e a contemplação permitem chegar à Ideia, objetivação da própria vontade, ou seja, atravessar o mundo fenomênico e o véu de Maia, que o encobre e olhar as coisas tais como são. O gênio, olho do mundo, o vê na sua verdade, porém, quando o revela, se reporta necessariamente aos outros espectadores que, para ver o que se produz nessa representação devem poder também ser dotados dessa capacidade, embora num grau menor e diferenciado, que permite a receptividade para o belo e o sublime, e portanto a fruição das obras de $\operatorname{arte}^{7}$; é o

\footnotetext{
${ }^{7}$ Schopenhauer, Arthur. Die Welt als Wille und Vorstellung. $\$ 37$ Haffmans Verlag Taschenbuch, B. 1, 1991, Leipzig, p. 263. Tradução Brasileira: Jair Barboza, UNESP 2005, São Paulo, p. 264.
} 
que salva, de algum modo, o gênio do solipsismo, dando sentido à produção do gênio.

Gerard Lebrun, ao expor as características do gênio em Kant, destaca justamente a comunicabilidade garantida pela exigência da universalidade do juízo de gosto. É ao “entusiasmo estético" que Lebrun dirige sua crítica, por ter Schopenhauer caracterizado o gênio criador como indivíduo excepcional e isolado, que consegue ver uma verdade oculta, mas já existente, para o conhecimento comum. ${ }^{8}$ Lebrun cita a Antropologia onde Kant diferencia encontrar (erfinden) de descobrir (entdecken). A arte não descobriria algo já existente, segundo Kant, mas encontraria, ou melhor, inventaria algo que ainda não é. ${ }^{9}$ É o recurso às Ideias platônicas que levou Schopenhauer a ter essa concepção do gênio, pois, é através do conhecimento das Ideias que ele pode ver além das aparências. Lebrun lembra o mito da caverna em Platão, donde o gênio emergiria para o contato com o real. A menção a Platão é explícita no texto do Mundo, porém é preciso investigar a modulação que a noção de Ideia tomada de empréstimo ao filósofo grego recebe no pensamento de Schopenhauer. É preciso esmiuçar o sentido que em Schopenhauer adquire a contemplação das ideias. O que a ideia propriamente revela, na criação do gênio? É algo já existente que é descoberto, algo já dado? - o que impediria a criação ou o encontro de algo, produzido pela atividade do gênio? Ao afirmar que a $3^{\text {a }}$ Crítica foi "deformada" no sentido de uma "metafísica entusiasta" ${ }^{10}$, Lebrun liga Schopenhauer a Jacobi, para Kant o delirante, Schwärmer, que "se vale de uma razão intuitiva", linguagem divina que Kant se recusa a entender. ${ }^{11}$ Não se poderia, numa via oposta, entender a metafísica do belo, não no sentido da deturpação da filosofia transcendental kantiana, mas como dando as condições de possibilidade de explicar o sentimento do belo, tanto na bela natureza, como na obra de arte, por uma via intuitiva, desarmando-se de vez do arcabouço da lógica e da abstração? Aqui é preciso lembrar tanto da crítica de Schopenhauer a Jacobi, ao rejeitar "uma razão que pressente o Absoluto", quanto da crítica à razão intuitiva em Schelling, capaz de chegar ao Absoluto, na referência que ele faz à filosofia da

\footnotetext{
${ }^{8}$ Ver Lebrun, G. Kant et la fin de la méthaphisique. Armand Colin, 1970, p. 406 e tradução bras. Martins Fontes, São Paulo - C. A. Moura - p. 553.

${ }^{9}$ Kant, I. Anthropologie in pragmatischer Hinsicht. Werke, B10, WBG Wilhelm Weischedel, Darmstadt, p. 545. BA 160.

${ }^{10}$ Lebrun, G. Idem, ibidem. p. 321. Tradução bras., p. 436.

${ }^{11}$ Idem, ibidem. p. 408. Ver carta a Hammann, 6 de Abril de 1774 - citada por Lebrun, p. 408. Tradução, p. 356.
} 
identidade; essas passagens mostram como Schopenhauer manifesta a sua aversão a uma "razão mística", no que não estaria tão longe de Kant.

Segundo Heimsoeth, no ensaio "Kant e Platão" o primeiro retoma na primeira Crítica o termo Ideia de Platão. Ao mesmo tempo em que ele louva a sua linguagem sublime e elevação do espírito, toma distância da doutrina platônica das ideias, advertindo do perigo dos "excessos" e de uma dedução mística das ideias indevidamente hipostasiadas. ${ }^{12}$ Heimsoeth cita a passagem onde Kant com fino humor critica Platão com a bela imagem da livre pomba que voa no ar, e que imagina "ser mais bem sucedida no espaço sem ar"; ... "do mesmo modo..., Platão teria abandonado o sensível e, nas asas das ideias se lançado no espaço vazio do puro entendimento" ${ }^{\prime 3}$. Mas é Platão quem no domínio da moral, se coloca em oposição diametral a Epicuro, o mais ilustre filósofo da sensibilidade e também a todos os moralistas que partiram da observação dos fatos e da natureza humana para alcançar um sentido moral. Como o "cabeça dos noologistas" (Haupt der Noologisten), buscou a medida e o ideal de todo comportamento autenticamente moral, no suprassensível e não os fenômenos. Na reflexão número $6842^{14}$ Kant diz que Platão constitui a moral a partir das ideias e não da inclinação e da experiência, só que Platão buscava a Ideia da moral em Deus. Por isso, Platão é considerado o "gênio delirante" que se excede nas Ideias, mas, ao mesmo tempo, podemos pensar também em Platão, quando ele diz que não há progresso do espírito sem se imitar o que já se sabe, numa nova relação ${ }^{15}$.

Se na Crítica da Razão Pura, as ideias da razão têm uma função reguladora, permitindo pensar numa totalidade da experiência e, na segunda Crítica, a de tornar possível uma moral racional, na Crítica do juízo, as ideias estéticas têm por função "animar o espírito, dando-lhe uma perspectiva sobre um campo de representações de um mesmo gênero que se estende a perder de vista" ${ }^{16}$, essas representações da imaginação tendem a algo além dos limites da experiência e procuram se aproximar dos conceitos da razão. "As ideias estéticas dão muito a

\footnotetext{
${ }^{12}$ Heimsoeth, H. Kant und Plato. In Kant Studien, n. 56, 1965, p. 349.

${ }^{13}$ Idem, ibidem. p. 350.

${ }^{14}$ Heimsoeth, H. Kant und Plato, p. 354, XIX 177 - Platão: Moral a partir da ideia não de acordo com as inclinações ou a experiência. Só que ele buscava sua ideia em Deus ou construia seu conceito de Deus a partir dessa ideia.

${ }^{15}$ Idem (veja-se Reflexion, 788 - XV 340 Ak Ausgabe).

${ }^{16}$ Kant, I - Kritik der Urteilskraft - Eine ästhetische Idee dient eigentlich aber um das Gemut zu beleben, indem sie ihm die Aussichten ein unabsehliches Feld verwandter Vorstellungen erröffnet. Weischedel, vol. 8, p. 415 A 193, B 195.
} 
pensar" "17, mas não dão nenhum pensamento determinado. É uma intuição da imaginação a qual não corresponde um conceito adequado e que nunca pode tornar-se conhecimento, desde que se refere ao suprassensível por meio de um conceito indeterminado, ao qual não pode ser dada qualquer intuição, Kant a nomeia "uma representação inexponível da imaginação" à diferença da ideia racional que é "um conceito indemonstrável da razão" 18 É o gênio a faculdade que apresenta (darstellt) as ideias estéticas ${ }^{19}$. A imaginação no gênio aparece como livre de regras, mas, no entanto, como espontaneamente final (unabsichtliche Zweckmässigkeit). Dando-se um livre acordo entre a livre imaginação e o entendimento, essas faculdades dispõem-se no gênio "numa tal proporção que só pode ser engendrada pela natureza do sujeito, não pelas regras da ciência ou da imitação mecânica"20, não gerando assim qualquer conhecimento objetivo. A originalidade do gênio em Kant impede que seu produto seja imitado, ele pede apenas que seja exemplar para outro gênio, já que ele é um favorito da natureza, que nela conta com raros exemplares.$^{21}$

A aproximação entre Schopenhauer e Kant está na distância entre a obra de arte e o conhecimento da ciência e da técnica, e o que os separa é o conhecimento estético objetivo e intuitivo da coisa em si ou Vontade por meio da Ideia, que marca a metafísica do Belo. Segundo Gerard Lebrun, o juízo de gosto em Kant não é um outro tipo de conhecimento, mas "uma outra modalidade não-teórica, de nossa relação ao aparecer". ${ }^{22}$

$\mathrm{O}$ conhecimento intuitivo que o gênio propiciaria por meio da obra, leva à interpretação de uma vertente mística na estética schopenhaueriana, que se manifesta na contemplação e na atitude desinteressada do sensível do sujeito puro do conhecimento, o que prenunciaria a "negação da vontade". Sem discutir o teor dessa proximidade entre ética e estética, e deixando ainda de lado o significado da negação da vontade, origem dessa pecha de misticismo, em que a contemplação do belo seria uma espécie de "quietivo" da vontade anunciando a sua negação, vamos nos ater, para repensar essa leitura que vê na estética schopenhaueriana uma retomada da metafísica clássica, à tentativa de explicitação do caráter desse

\footnotetext{
${ }^{17}$ Idem, p. 413 A 190, B 193.

${ }^{18}$ Idem, ibidem.

${ }^{19}$ A 190 B192, p. 413.

${ }^{20}$ B 200 A 198, p. 419.

${ }^{21}$ B 200 A 198, p. 419.

${ }^{22}$ Lebrun, G. Kant et la fin de la Métaphysique. Armand Colin, Paris, 1970, p. 321. Tradução bras., 436.
} 
conhecimento que a arte propicia e da verdade que nele estaria contida. A afinidade entre gênio e loucura, exposta no parágrafo 36 do Mundo, enfatiza, além disso, o platonismo e o "misticismo" da estética schopenhaueriana e da sua concepção de Gênio. O gênio platônico teria como dote a "mania" dos antigos como um atributo divino, permitindo um livre acesso ao suprassensível e autorizando o epíteto de "Schwärmer", com que Kant brinda Jacobi e Platão. Schopenhauer pretende apresentar "a pura razão intelectual desse parentesco entre a genialidade e a loucura, com intuito de esclarecer a essência própria da genialidade". 23

Este parentesco não se refere diretamente a uma constituição anormal fisiológica do gênio ou mesmo do louco, mas a um distúrbio afetivo da memória, como organização da cadeia dos eventos e pensamentos passados. Mas apesar da memória referir-se obviamente às cadeias causais e abstratas, pois pressupõe a linguagem, ela pertence à Vontade, pois é esta em última instância a responsável pela ordenação das ocorrências de imagens. Em que sentido isso se dá? Há memórias que trazem fatos que desagradam à vontade, ou mesmo causam sua repulsa por serem extremamente doídos. Diante deles a Vontade os afasta do pensamento e impede que tais representações entrem nas cadeias das lembranças, produzindo uma interrupção no seu curso, um vazio, uma lacuna. Ao preencher esta lacuna com um conteúdo fantasioso, instaura-se o que Schopenhauer define como loucura, uma disfunção psicológica. Ora, a similaridade com o gênio provém justamente do corte nas cadeias de representações causais e abstratas, na ausência das ligações promovidas pelo princípio de razão, necessárias para constituir o conhecimento quotidiano e o científico, baseados na interação dos objetos. Ao destacar a ideia de um objeto, o gênio faz uso de um modo de conhecer estranho às representações interligadas pelo princípio de razão e, nesse sentido, pela quebra nas sequências de representações que também se dá na loucura, donde o parentesco entre a genialidade e a loucura. Nas observações feitas nos hospitais psiquiátricos de fato Schopenhauer se refere a indivíduos de inteligência aguçada e com características de genialidade, mas cujo desenvolvimento teria sido impedido justamente pela loucura. ${ }^{24}$

\footnotetext{
23 (grifo meu) - WWV § 36, p. 247. Tradução bras., p. 261.

${ }^{24}$ Schopenhauer, A. Die Welt. § 36, p. 259 ss. Tradução bras., p. 261.
} 
O gênio, mesmo apresentando algum comportamento peculiar, característico de sua originalidade, não se caracterizaria pela doença como impossibilidade de remontar a seu passado, nem pelo preenchimento das lacunas com conteúdos fantasiosos, marca do caráter patológico. O que Schopenhauer parece querer frisar com essa proximidade é o fato de que a capacidade do gênio em conhecer além do princípio de razão, em conhecer diretamente o singular, o tornaria canhestro no trato das relações cotidianas. Além disso, o fato de ser dotado pelo seu intelecto de um forte poder intuitivo poderia afetar sua capacidade de encadear deduções nos raciocínios abstratos, e vice-versa; aliás, aquele que prima pela aptidão ao conhecimento abstrato, dificilmente seria dotado de genialidade como, por exemplo, o matemático. ${ }^{25}$ E o filósofo? Sabemos que Schopenhauer considera Kant o grande gênio. Assim, se Kant errou ao dar primazia à abstração sobre o conhecimento intuitivo, foi também capaz de descobertas decisivas, tais como a distinção entre fenômeno e coisa em si e a entre caráter empírico e inteligível que mostram a força de sua intuição certeira. A filosofia requer, pois, uma dose de genialidade e quanto a sua própria filosofia, Schopenhauer a considera, ao mesmo tempo, ciência e arte. Ciência, enquanto linguagem que se vale de abstrações, e arte enquanto intuição criadora.

Já que as ideias significariam para Schopenhauer a possibilidade de ascensão a um conhecimento objetivo, é esta forma da objetividade que permitiria qualquer comunicação entre o gênio, olho do mundo, e os outros homens. Ora, a arte se extinguiria no seu criador, se não houvesse uma ponte possível entre ele e os demais homens. Não haveria fruição estética se os demais não fossem dotados de uma certa genialidade, embora em tom menor. ${ }^{26}$ Assim, o alegado solipsismo do gênio se ameniza, desde que não nos esqueçamos da necessidade de mostrar o que o mundo é ou poderia ser, por meio da obra de arte; esta tem a potência até mesmo de completar a natureza naquilo que ela não foi capaz de realizar. ${ }^{27}$ Em Kant, como frisa Lebrun, a comunicação é peça fundamental na concepção do gênio e do gosto, já que ele não é individuo singular, mas manifesta a natureza do homem, a natureza dá a regra ao gênio, se aí se entender natureza não como o conjunto de objetos da experiência possível, mas como a natureza do homem que bascula entre

\footnotetext{
${ }^{25}$ Idem, ibidem. p. 257. Tradução bras., p. 258.

${ }^{26}$ Idem, ibidem, § 37, p. 263. Tradução bras., p. 264.

${ }^{27}$ Idem, ibidem, § 36, p. 234. Tradução bras., p. 255.
} 
o sensível e o suprassensível. O juízo é, para Kant, garantia da exigência de universalidade e desse modo de uma certa objetividade; em contrapartida, para Schopenhauer, que junto com a abstração afasta qualquer ajuizamento prévio no campo da estética, o caráter objetivo só pode ser garantido pelo chamado conhecimento metafísico do belo, tornado possível pelo contato com a Ideia, como objetivação da Vontade, afastando o caráter ilusório das representações submetidas ao princípio de razão, por não estarem voltadas para encontrar a verdade, mas terem por função dirigir o indivíduo para a satisfação de seus interesses e necessidades. Se há um “outro tipo de conhecimento" na metafísica do Belo, este é estranho ao conhecimento teórico, e não seria excessivo defini-lo de modo semelhante ao que diz Lebrun da reflexão, isto é, como "uma outra modalidade não-teórica da nossa relação ao representar"... ${ }^{28}$ A nosso ver, a metafísica do belo mantém o caráter imanente, embora se dê ares de atingir uma verdade transcendente, cujo veículo seria o conhecimento privilegiado que o gênio pode alcançar. Este não é tão somente um ser de exceção, o único que ousa sair da caverna, e em cuja volta se vê ofuscado pelo brilho da luz verdadeira, mas alguém que revela uma verdade que está oculta aos demais, mas que todos poderiam atingir, desde que seu caráter inteligível é a expressão da vontade em cada um, confundindo-se com ela. O que impede o conhecimento puro é uma espécie de “distração" proporcionada pelo conhecimento interessado pelos objetos que afetam a vontade e, portanto, a determinam, mas que, como representações interligadas, dão a ver tão somente as relações que mantêm entre si e com nosso querer. Se a força do intelecto for suficiente para afastar tal impedimento, chega-se ao conhecimento desinteressado e por isso objetivo. Daí a necessidade de expor as características do gênio, tais como a força do seu intelecto, que, ao mesmo tempo, é sustentada por uma vontade forte. O que faria dele esse ser de exceção seriam esses atributos naturais, que além de psicológicos são fisiológicos; mas aqui, justamente, não se pode esquecer que, ao se manifestar no mundo, é a vontade cindida (entzweit) que dirige na sua luta intrínseca pela matéria, a conformação de todos os seres, inclusive a de cada homem. Donde tal determinação do gênio não é extrínseca à natureza, mas produto da vontade imanente nela.

\footnotetext{
${ }^{28}$ Ver nota 18.
} 
É preciso, além disso, questionar essa verdade objetiva trazida pelo gênio e contrapô-la ao conhecimento interessado, submetido ao princípio de razão, ao conhecimento estético. Quando Schopenhauer fala, no primeiro livro, de conhecimento intuitivo, ele se refere sempre à representação, que não se refere a nenhum objeto exterior a ela, ou seja, ela é o próprio objeto como construto do entendimento pela lei da causalidade. No terceiro livro, ao definir a Ideia como objetivação da vontade, ele estaria propondo, com a noção de Ideia, um conhecimento universal como um reflexo da Vontade, e não um universal lógico obtido por meio da abstração das características comuns a vários objetos (Gegenstände). A Ideia, como universalia ante rem, como primeira objetivação da vontade, seria uma condição de determinação, fora do tempo, espaço e causalidade, lugar da unidade prévia à multiplicidade das representações espaciotemporais. Este universal configura o campo das diferentes modulações ou formas quer dos seres da natureza, enquanto espécie, quer do homem enquanto caráter inteligível, quer da obra do gênio, enquanto belo universal. Essa verdade não se expressa pela adequação a algo preexistente, mesmo porque um referente anterior é inencontrável, mas se refere a uma forma de expressão possível. Assim, ao se referir à fantasia (Phantasie), necessária não só para o artista, mas para o filósofo, diz Schopenhauer: "A fantasia amplia o círculo de visão do gênio segundo a quantidade." Contudo, também segundo a qualidade, a saber: "os objetos efetivos são apenas exemplares imperfeitos da ideia que nelas se expõe; por isso o gênio precisa igualmente da fantasia para ver nas coisas não o que a natureza realmente formou, mas o que se esforçava por formar, porém devido à luta de suas formas entre si, não conseguiu levar a bom termo." Portanto, a fantasia serve para ampliar seu círculo de visão para além dos objetos que se oferecem à sua pessoa na realidade $^{29} \ldots$ e "a força da fantasia é até mesmo condição do gênio"30. Ao perguntarmos pelo que está "além dos objetos que se oferecem na realidade (Wirklichkeit)" - sabemos que nela não encontraremos mais do que representações, e esse além não aponta para algo suprassensível, mas para o possível contido na Ideia, como o que é universal ante rem. O gênio não é o demiurgo, que toma o lugar da divindade ou é inspirado por ela, mas o intérprete da vontade, o seu tradutor, tal como das forças naturais que expressam as ideias, tal como em Kant

\footnotetext{
${ }^{29}$ Idem, p. 254. Tradução bras., p. 255.

${ }^{30}$ Idem, p. 254, § 36. Tradução bras., p. 256.
} 
ele é um "favorito da natureza". Respeitando o caráter imanente que Schopenhauer dá à sua filosofia, não há como interpretar a estética ou metafísica do belo, como uma "metafísica entusiasta", que se excede ao buscar fora do mundo e da vontade que nele se expressa, alguma realidade exterior, que seria a sua verdade. $O$ sentimento estético traz a imagem do próprio mundo, na qual o sujeito se vê e se funde com o objeto na contemplação da ideia, suprimindo a mera representação e seus polos, sujeito e objeto.

Os traços platônicos que marcam fortemente a estética de Schopenhauer são de certo amenizados, quando se combinam com os traços herdados de Kant, dando um feitio próprio e inconfundível à metafísica do belo. Torna-se assim possível conciliar a Metafísica do belo com a imanência que o próprio Schopenhauer atribui à sua filosofia ${ }^{31}$.

\footnotetext{
${ }^{31}$ Schopenhauer, A. Fragmente über die Geschichte der Philosophie. Idem, p. 131. Tradução bras. Maria Lúcia Cacciola. Ed. Iluminuras, São Paulo, 2003, p. 118.
} 


\section{Referências Bibliográficas}

Kant, I. Antropologie in pragmatischer Hinsicht. Werke, vol.10. WBG Wilhelm

Weischedel, Darmstadt, 1975.

Kant, I. Kritik der Urteilskraft. Weischedel, vol. 8.

Heimsoeth, "Kant und Plato" in Kant Studien, n. 56, 1965.

Lebrun, G. Kant et la fin de la méthaphisique. Armand Colin, 1970, p. 406 e tradução bras. Martins Fontes, São Paulo. C.A. Moura.

Schopenhauer, A. Fragmente über die Geschichte der Philosophie. Idem. p.131. Tradução bras. Maria Lucia Cacciola, Ed. Iluminuras, São Paulo, 2003.

Schopenhauer, A. "Kritik der kantischen Philosophie" Haffmans Taschenbuch, Leipzig, 1988, p. 670. Tradução, Ed Abril, São Paulo, 1980.

Schopenhauer, A. Die Welt als Wille und Vorstellung. Haffmans Verlag Taschenbuch. B. 1, 1991, Leipzig, p. 263. Tradução brasileira: O Mundo como Vontade e como representação, Jair Barboza, UNESP, 2005, São Paulo. 